\title{
Charging Station and Power Network Planning for Integrated Electric Vehicles (EVs)
}

\author{
Guozhong Liu ${ }^{1}$, Li Kang ${ }^{1}$, Zeyu Luan ${ }^{2}$, Jing Qiu ${ }^{2, *}$ and Fenglei Zheng ${ }^{3}$ \\ 1 School of Electrical Engineering \& Intelligentization, Dongguan University of technology, \\ Dongguan 523808, China \\ 2 School of Electrical and Information Engineering, The University of Sydney, Sydney, NSW 2006, Australia \\ 3 Dongguan Power Supply Bureau, Dongguan 523808, China \\ * Correspondence: Jeremy.qiu@sydney.edu.au
}

Received: 8 May 2019; Accepted: 3 July 2019; Published: 5 July 2019

check for updates

\begin{abstract}
The optimal location and size of charging stations are important considerations in relation to the large-scale application of electric vehicles (EVs). In this context, considering that charging stations are both traffic service facilities and common electric facilities, a multi-objective model is built, with the objectives of maximizing the captured traffic flow in traffic networks and minimizing the power loss in distribution networks. There are two kinds of charging stations that are considered in this paper, and the planning of EV charge stations and distribution networks is jointly modelled. The formulated multi-objective optimization problem is handled by a fuzzy membership function. The genetic algorithm (GA) is used to solve the objective function. In case studies, a 33-node distribution system and a 25-node traffic network are used to verify the effectiveness of the proposed model. The location and capacity of two kinds of charging stations are designed in the case studies, after which the impact of the battery on the captured traffic flow is analyzed as well.
\end{abstract}

Keywords: electrical vehicles; charging station planning; traffic flow; power loss; multi-objective optimization

\section{Introduction}

With the development of the global economy, the demand and consumption of energy in various countries have been growing steadily. Environmental pollution and the energy crisis have also attracted attention. According to a survey from the World Bank, $\mathrm{CO}_{2}$ emissions in 2013 and 2014 were 4.988 and 4.97 metric tons per capita, respectively. The high $\mathrm{CO}_{2}$ emissions are mainly a result of the coal-based energy structure [1]. More than half of petroleum is used in transportation. Fuel vehicles account for the largest proportion of the transportation sector. At the same time, the automobile exhaust is one of the main sources of environmental pollution. The development of the electric vehicle (EV) industry is an important measure to reduce greenhouse gas emissions and reduce dependence on fossil fuels [2]. With the advance of EV technology, especially the development of battery technology, and the strong policy support in some countries, EVs have developed rapidly over the past decade [3].

Many EVs increase the load in power grids, which will have a negative impact on the safe and reliable operation of power systems. However, except for these negative effects, EVs can bring considerable economic benefits to the distribution system through optimal planning, such as vehicle-to-grid (V2G) technology [4]. According to statistics, the driving time of $80 \%$ of vehicles is about $1 \mathrm{~h}$ per day, and they are idle for $95 \%$ of the day. The energy stored in EVs is considerable [5]. V2G technology can ultimately idle energy appropriately. Idle vehicles can transfer their energy into power grids to lighten the burden on power grids and adjust node voltage. Compared with the traditional method, the response of EVs is faster. 
The concept of V2G was first proposed by an American scientist, Amory Bloch Lovins, in 1995, and was then further explored by the Delaware University research team, which was led by Professor Willett Kempton [6]. EVs can discharge to the grid at peak power load, with a higher price, and charge, with a lower price. The load of the power grid can be smoothed by V2G technology and EV users can also earn the difference in electricity charges/tariffs. Kempton led the team to further study the V2G technology and successfully connected an EV to the grid in 2007.

In terms of the feasibility of EVs participating in the frequency regulation of power grids, the feasibility of bi-directional energy flow between the EV and the power grid and the participation of the EV in the frequency modulation was verified in the work of [7]. The authors in [6] studied the California electricity market, and the results showed that it was feasible and practical for EVs to participate in frequency modulation.

In terms of the economic benefits of providing frequency adjustment, the battery loss was considered, and the economy of frequency modulation service provided by EVs was adjusted, in the work of [8]. The result showed that the benefit of EV participating in frequency modulation was higher than the cost of the battery. On the basis of V2G technology, the average economic benefits of one EV, when adding EVs into the American ISO frequency modulation market, was analyzed in the work of [9]. The result showed that the frequency modulation provided by EVs could bring considerable economic benefits to owners. The authors in [10] proposed an optimal control method, with centralized V2G participation in system frequency modulation, and analyzed the problem of maximizing the benefit, considering the energy constraint of the EV battery. The relationship between the load state and benefit of the EV battery was obtained. In the work of [11], a simulation-optimization model was developed to maximize the EV battery in privately owned electric vehicles. In the work of [12], a mixed-integer non-linear (MINLP) optimization approach was considered in relation to government policy, the location of electric substations and urban roads, and the station development cost for the optimal placement and sizing of the fast charging stations. The results showed that the location and the size of fast charging stations were important for reducing the EV energy loss and station electrification cost.

In terms of the control strategy of EVs entering the network, there are two modes: centralized network access and decentralized network access. The frequency modulation control strategy is different for different network access modes. In terms of the centralized network access mode, several different control strategies for the frequency modulation service provided by EVs were proposed, in the work of [13], to realize a reasonable distribution for V2G participation. The authors in [14] proposed a method for tracking a secondary frequency control signal and realized the control allocation of units by model predictive control strategy y. In terms of the decentralized network access mode, a distributive autonomous strategy for frequency modulation was proposed in the work of [15]. This method considered the demand of EVs and modulated the frequency according to the frequency deviations. The authors in [16] used the method of adaptive frequency drop to meet the demand of the frequency.

The charging mode is the most important energy supply mode of EVs, but there are still many problems in practice. Therefore, the charging method is still a research priority in relation to EVs. At present, there are three main types of standard charging posts for EVs: AC level 1 (slow charging), AC level 2 (fast charging), and DC fast charging [17]. The AC level 1 charging post can provide a voltage of about $120 \mathrm{~V}$ and charging current of 12-20 A, which is suitable for the long-term charging of EVs. Therefore, it is usually installed at homes, hotels, airports, and offices [18]. The power of the AC level 1 charging post is about $1-2 \mathrm{~kW}$, which can be directly connected to power systems. The early investment of the AC level 1 charging method is low. Considering the ordinary household load, which is only $0.5-3 \mathrm{~kW}$, and the peak load concentration from 18:00 to 12:00 (this coincides with the EV charging time), the pressure brought about by AC level 1 posts cannot be ignored. It can be predicted that the peak load of residential areas will be greatly increased with the increase in EV penetration. A massive load not only increases the power supply pressure of distribution networks, but also requires many augmentations and extensions of the current power system, thus resulting 
in additional investment and construction costs [19-21]. A higher charging power can be provided by AC level 2 and DC fast charging posts, which are usually installed at public charging stations to provide a fast charging service and reduce charging time. A super charging post, researched by Tesla, can provide $20 \mathrm{~kW}$ of charging power. EVs can be fully charged in $30 \mathrm{~min}$. It is predicted that plug-in EVs will be more widely used with the proliferation of EVs. Violent and random load fluctuations will seriously threaten the stability of distribution networks. Therefore, there are many potential threats in the large-scale disorderly charging of EVs.

The charging dispatch problem of EVs is an important issue in the research on EVs. In the current practice of EVs, because of the lack of information interaction, the choice of the charging locations of EVs often depends on empiricism, which is likely to lead to disorderly charging, local charging overload, and a low utilization of charging facilities. With the rapid development of information interaction, smart grids and intelligent transportation can ensure full information interaction and provide the possibility for coordinated EV dispatch. The charging dispatch can provide more flexible charging time and optimize resource allocation and system benefits. At present, there are many research works on the charging dispatch of EVs, which can be divided into deterministic dispatch (the optimal dispatch, with all information determined) and stochastic dispatch (the real-time dispatch, with unknown or incomplete information in the future). Considering the particularity of the online dispatch problem, most existing works consider deterministic problems, which can be subdivided into the demand response, joint dispatch of the power grid operation, and auxiliary service of power grids.

The EV charging dispatch usually gives priority to its own interest to respond to changes in external factors, such as the electricity price and operating income [22-24]. A novel vehicle-to-vehicle (V2V) mechanism was proposed, in the works of $[25,26]$, to allow electricity to be exchanged between EVs, based on the concept of V2G. This mechanism further exploited the potential of EVs as an energy storage. At the same time, in the works of $[25,26]$, a distributed trading mechanism was designed to ensure the fairness of V2V. The authors in [27] tried to minimize both the charging cost and battery loss at the same time. However, the result showed that the two objectives conflicted. Therefore, the genetic algorithm was used to find the Pareto frontier in the formulated multi-objective problem.

The joint dispatch of the power grid operation refers to the co-operation of the large-scale EV charging dispatch and power system operation. The authors in [28] were among the first to introduce the EV charging dispatch problem into the optimal power flow problem. The semidefinite programming (SDP) method was employed to optimize the power dispatch and charging of EVs in a time-space domain. The authors in [29] proposed a novel real-time charging control strategy for EVs, which effectively solved the problem of EVs randomly accessing the power grid. The optimization of maximum sensitivity screening was employed to minimize the generation cost and power loss in the power grid.

The controllable charging and discharging capability of EVs has a closer interaction with power grids. At the same time, EVs can effectively participate in the auxiliary service market. EVs can reduce the marginal cost of the power system and improve the economy by providing an auxiliary service. The authors in [30] constructed a novel V2G auxiliary service market and analyzed the feasibility of EVs participating in frequency modulation. The interaction between EVs and managers in the market was modeled using game theory, which proved that the distribution could balance the rated power grid frequency. The authors in [31] proposed a charging dispatch strategy for EVs participating in the auxiliary service market. On the basis of a hierarchical model, the decision was made by the look-ahead stochastic dynamic programming algorithm to reduce the auxiliary service cost and charging cost in wind farm regulation.

This paper aims to find the optimal approach to integrating the distribution network and traffic network. Normal charging stations and fast charging stations are the two kinds of stations that are considered in this paper. Compared with the previous paper, the contributions of this paper are summarized below. First, this paper considers both the distribution network and traffic network simultaneously in one system by the fuzzy multi-objective model. Second, considering the charging 
model over different time periods can better simulate the charging behavior of EVs. The remainder of this paper is organized as follows. Section 2 presents the problem description. Section 3 presents the proposed modeling. Section 4 presents the case studies. Section 5 presents the conclusions and future research challenges.

\section{Problem Description}

In this section, the problem is briefly described, including the combination of the traffic network and distribution network and the proposed strategy in this paper.

\subsection{Combination of the Traffic Network and Distribution Network}

In the field of transportation, the research aims to solve the problem of the location of service facilities. Most of the existing research focuses on the users and the optimization objectives and generally aims to reduce the cost of construction and travel. The charging demand of EVs is not concentrated on nodes, but rather on flows in the traffic network. Therefore, the traffic flow can be used to simulate the charging demand of EVs. The existing interception location models generally assume that all customers' flow can be captured, as long as there is a service facility on the path. However, in the EV charging station planning problem, the construction of the charging station at only one node may not meet the demand of EVs because of the limitation of the traveling distance (the traffic flow on this path cannot be fully captured). Therefore, on the path whose traffic flow can be fully captured, the construction of the charging station must meet the following demands:

(1) If there are charging stations at both the start point and the end point, the travel distance of EVs must be more than the length of the path; and

(2) If there is a charging station at only the start point or the end point, the travel distance of EVs must be more than twice the length of the path.

This paper uses traffic flows to simulate the charging demand with an interception model and considers some restrictive factors, such as the maximum travel distance of EVs. The objective is to choose appropriate nodes for constructing charging stations, aiming to maximize the traffic flow (to provide a charging service for more users).

Electricity charging station planning should consider not only the convenience of charging, but also the influence of the charging station on the power quality and the security and economy of the system operation. Therefore, it is a typical multi-objective optimization problem. Significant traffic network nodes are also significant load nodes in the distribution network. On the basis of this background, this paper assumes that part of the nodes on the distribution network overlap with significant traffic network nodes geographically (here, overlap means that the two points are located in the same small area, which is not necessarily strictly at a geographical point), as shown in Figure 1. However, the branches of the distribution network and the roads of the traffic network do not necessarily overlap. In addition, the EV charging station needs to meet the charging needs of EVs. Therefore, the candidate position of the charging station is selected at the overlap position of the traffic and distribution networks.

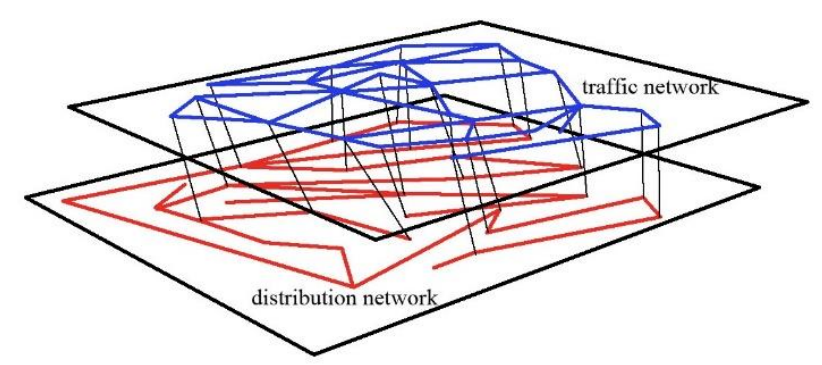

Figure 1. Geographical overlapping of the distribution network and traffic network. 


\subsection{Proposed Strategy}

In this paper, a fuzzy multi-objective model is proposed to deal with the two objectives, and the genetic algorithm (GA) is used to find the optimal solution. The overall objective is to maximize the captured traffic flow in the traffic network and minimize the power loss in the distribution network.

In the first stage, it is assumed that when an EV passes by a charging station, the owner accepts the charging service until the EV is fully charged, regardless of how much battery remains. Because of the widespread use of navigation and the driving experience of drivers, it is assumed that EV owners will choose the shortest path from the starting point to the destination. The Floyd-Warshall algorithm is used to find the shortest path between the start point and the end point [32]. At the same time, the traffic flow model is not complicated, and there are many research results to choose from, such as the equilibrium modeling framework [33] and gravity-space interaction [34]. Meanwhile, the gravity model is suitable for analyzing the distribution of trips within urban areas, and the distribution of the origin or destination of these trips is not limited to a few locations [35]. Therefore, the gravity-space interaction is used to simulate the traffic flow on each path. In the second stage, the capacity of the charging station should meet the daily charging demand, which is determined by the simulated vehicles' charging time. Different locations and capacities of the charging stations will cause varying degrees of impact on the power grid.

\section{Proposed Modeling}

In this section, the models of the captured traffic flow and the power loss are given first, followed by the fuzzy multi-objective model.

\subsection{Captured Traffic Flow}

The authors of [36] estimated the relationship between the plug-in electric vehicle (PEV) public charging infrastructure coverage and charging opportunity. The results showed that the driver travel destination was concentrated in a few popular places. Meanwhile, the scope of the use of a charging facility was also limited because of the limitation of the EV battery charging method. In practice, the daily routing of most vehicles is fixed. The traffic network is composed of these traffic flows. More traffic flows can be captured by the charging station, and a wider service range can be provided by this charging station. Capturing as much traffic flow as possible, with a limited number of charging stations, can reduce the construction cost and improve the service efficiency.

Objective:

$$
\max F_{t f}=\sum_{p \in P} f_{p} y_{p}
$$

Gravity-space interaction:

$$
f_{p}=\frac{W_{S} W_{E}}{1.5 d_{p}}
$$

where $f_{p}$ is the traffic flow on path $p ; y_{p}$ is the indicator function; $F_{t f}$ is the total captured traffic flow on the traffic network; and $W_{S}$ and $W_{E}$ are the weight coefficients on the start node and the end node of path $p$, respectively.

It is assumed that EVs cannot deviate from their shortest path $p$ during driving, and the maximum driving distance of the EV, with a fully charged battery, is $L$. If there is a charging station at the start point, the remaining available traveling distance is set to $L$. If not, the remaining available traveling distance is assumed to be equal to $0.5 \mathrm{~L}$. The reason is that, if an EV can reach the nearest charging station with $0.5 \mathrm{~L}$ remaining available traveling distance, it should be able to return with a remaining available traveling distance of over $0.5 \mathrm{~L}$. Two definitions are given here:

(1) If the node combination $h$ can provide a charging service for EVs on path $p$, and EVs can arrive at the destination, the node combination $h$ is called the effective node combination in path $p$. 
(2) A node combination is open if the all nodes in the node combination are set up at the charging stations.

It is obvious that only when a combination meets the two demands above can the traffic flow on path $p$ be captured.

$$
y_{p}=\left\{\begin{array}{cc}
1 & \sum_{g \in G_{p}} a_{p g} v_{g} \geq 1 \\
0 & \sum_{g \in G_{p}} a_{p g} v_{g}<1
\end{array},\right.
$$

where $a_{p g}$ is a binary variable that characterizes whether or not the node combination $h$ is effective, and $V_{g}$ is a binary variable that characterizes whether or not all the nodes in the node combination are set up at the charging station.

\subsection{Power Loss}

Because of the limitation of the EV battery capacity, EVs are commonly used in metropolises. The popularity of charging stations in metropolises is much greater than in rural areas. Technically speaking, the construction of charging stations in metropolises is easier than in rural areas. After connecting the charging stations of EVs to the distribution systems, the power flow of the system will change, and the power loss of the distribution system will change. The total power loss is not only determined by the base load of the grid, but is also related to the capacity and position of the charging station of EVs. The minimization of the power loss can be described as follows:

Objective:

$$
\min F_{p l}=\sum_{i=1}^{n} P_{\text {loss }, i}\left(\delta_{i} P_{i, k}, \delta_{i} Q_{i, k}\right),
$$

where $P_{i, k}$ and $Q_{i, k}$ are the real and reactive charging power of the type $k$ charging station on node $i$, respectively; $\delta_{i}$ is a constant; and $F_{p l}$ is the total loss. Two types of charging facilities are considered in this model: normal charging stations and fast charging stations. Normal charging stations operate $24 \mathrm{~h}$ a day, and fast charging stations only operate during rush hours to relieve charging pressure. In order to facilitate management and construction and to consider the total charging demand, the power of a normal charging station is set at an integer multiplier of $0.1 \mathrm{MW}$. The size of the fast charging station (FCS) is determined by the mean arrival rate, service demand, and demand.

A. Normal charging station

The charging station should first satisfy the users' demand for electricity, which is dependent on the daily charging time per EV and the number of EVs. In this paper, $\varsigma$ is employed here to represent the percentage of EVs that is not used in a day; $\xi$ is the percentage of EVs that would choose a normal charging station; and $v_{i, t}$ is the number of EVs that would charge at node $i$ at time $t$. The average charging times during a time period at node $i$ can be calculated as follows:

$$
V_{i}=\frac{(1-\varsigma) \xi \sum_{t \in T} v_{i, t}}{\sum_{i \in N^{D}} \sum_{t \in T} v_{i, t}}, \forall i \in N^{D} .
$$

The charging number of EVs and overall daily charging demand will be estimated under uncertainty. Herein, $\tau$ is the number of EVs that can be serviced by one charging pole at the same time.

Number of charging poles:

$$
M_{i}=\frac{v_{i, t}}{\tau}, \forall i \in N^{D}
$$

Charging power in time $t$ :

$$
P_{i, t}^{c p}=\left\{\begin{array}{cc}
v_{i, t} P^{c p} & v_{i, t} \leq M_{i} \tau \\
P_{i}^{c p, \max } & \text { otherwise }
\end{array}, \forall i \in N^{D}, \forall t \in T,\right.
$$




$$
P_{i}^{c p, \max }=M_{i} P^{c p}, \forall i \in N^{D},
$$

where $M_{i}$ is the maximum number of charging posts at node $i$; and $P^{c p}$ and $P_{i}^{c p, \max }$ are the fixed output power of the charging post and its maximum value, respectively.

B. Fast charging station

Because the driving distance of EVs is short, the FCS is important in providing electricity for EVs during peak demand hours. Different from the normal charging stations, FCSs have a large charging power, and EVs can be charged to full more quickly. As the service of FCSs is based on a first-come first-served (FCFS) rule, the waiting time for EVs that have just arrived is determined by the mean arrival rate $\lambda_{k}^{P K}$, mean service rate $\omega$, and FCSs' capacity $s_{k}$.

The mean arrival rate $\lambda_{k}^{P K}$ is related to the quality of EVs and also to the traffic flow at this node:

$$
\lambda_{k}^{P K}=\max \left\{\lambda_{k, t} \mid \lambda_{k, t}=N(1-\varsigma)(1-\xi) \frac{f_{k}}{F_{t f}}, \forall t \in T\right\}, \forall k \in \Omega^{k},
$$

where $f_{k}$ is the captured traffic flow by the $k$ th fast charging station. According to the $M / M / s$ queuing theory, the mean waiting time is the inverse, proportional to the mean service rate $\omega$ and FCSs' capacity $s_{k}$.

Objective:

$$
\min s_{k} \text {. }
$$

Subject to:

$$
\begin{gathered}
W_{k}^{P K}<W^{\text {allowes }} . \\
W_{k}^{P K}=\frac{\left(\mathrm{s}_{k} \rho_{k}^{P K}\right)^{s_{k}} \rho_{k}^{P K}}{\lambda_{k}^{P K}\left(\mathrm{~s}_{k}\right) !\left(1-\rho_{k}^{P K}\right)^{2}} P_{0, k}, \forall k \in \Omega^{k}, \\
P_{0, k}=\left(\sum_{n=0}^{s_{k}-1} \frac{\left(s_{k} \rho_{k}^{P K}\right)^{n}}{n !}+\frac{\left(s_{k} \rho_{k}^{P K}\right)^{s_{k}}}{\left(\mathrm{~s}_{k}\right) !\left(1-\rho_{k}^{P K}\right)}\right)^{-1}, \\
\rho_{k}^{P K}=\frac{\lambda_{k}^{P K}}{s_{k} w}, \forall k \in \Omega^{k},
\end{gathered}
$$

where $W_{k}^{P K}$ and $W^{\text {allowed }}$ are the waiting time at the $k$ th FCS during peak time and its maximum value, respectively; and $\rho_{k}^{P K}$ is the occupied rate of the $k$ th FCS. The objective is to minimize the size of FCSs to decrease the cost of construction. Simultaneously, the size of FCSs should be large enough to ensure that the mean waiting time can be limited during the period with the maximum mean waiting time. Equation (10) calculates the mean waiting time with Little's law in the queuing theory, and the result is donated by the $P_{0, k}$, which is described in Equation (11). Equation (12) gives the occupied rate of FCSs. After the size of FCSs has been determined, the charging power of the FCS can be estimated by Equations (13)-(15).

$$
\begin{gathered}
P_{k, t}^{F C S}=\rho_{k, t} s_{k} p^{F C S}, \forall \mathrm{k} \in \Omega^{k}, \forall t \in T \\
P_{k}^{F C S, \max }=s_{k} p^{F C S}, \forall \mathrm{k} \in \Omega^{k} \\
\rho_{k, t}=\frac{\lambda_{k, t}}{s_{k} w^{\prime}}, \forall \mathrm{k} \in \Omega^{k}, \forall t \in T
\end{gathered}
$$

The FCS aims to provide a fast charging service for EVs and solve the charging congestion during peak charging periods. A high operation power can have a huge influence on the power grid. Therefore, the FCSs only operate during peak charging hours. Here, it is assumed that the time period with over $80 \%$ of the maximum charging quantity is the peak charging hour, and the location of FCSs is the node with the highest traffic flow. Some limitations of power systems are given here:

1) Limitation of the capacity of charging stations: 
The primary purpose of charging stations is to meet the daily charging demand of users. Therefore, the rate capacity of charging stations should not be less than the requirement of the maximum load.

$$
\sum_{i=1}^{n} \sum_{k=1}^{m} \varphi_{i, k} P_{i, k} \geq P_{i, \max }
$$

where $\varphi_{i, k}$ is a binary variable that characterizes whether or not the type $k$ station is set up at node $i$; and $P_{i, \max }$ is the maximum limitation of real power.

2) Limitation of the number of charging posts:

Considering the shortage of urban land resources, the number of charging poles should be limited to avoid the waste of idle resources.

$$
\sum_{i=1}^{n} \sum_{k=1}^{m} \varphi_{i, k}<M_{i}
$$

3) Limitation of the type of charging station:

In reality, only one type of charging station can be built at a node.

$$
\sum_{i=1}^{n} \sum_{k=1}^{m} \varphi_{i, k} \leq 1
$$

Limitation of the power flow:

After EVs are connected with the distribution network, the power flows of the distribution network will change. The power at each node and the power flow on each branch should not be greater than the limits of the distribution network to avoid damage to power grids.

$$
\begin{gathered}
P_{i, \text { min }} \leq P_{i} \leq P_{i, \text { max }} \\
Q_{i, \text { min }} \leq Q_{i} \leq Q_{i, \max } \\
P_{i}=V_{i} \sum_{j \in i} V_{j}\left(G_{i j} \cos \theta_{i j}+B_{i j} \sin \theta_{i j}\right) \\
Q_{i}=V_{i} \sum_{j \in i} V_{j}\left(G_{i j} \sin \theta_{i j}-B_{i j} \cos \theta_{i j}\right)
\end{gathered}
$$

Equations (19) and (20) limit the range of real power and the reactive power produced by the generators at node $i$, respectively, and Equations (21) and (22) show the AC power models at node $i$.

Equation (23) limits the power flow on the branch between node $i$ and $j$.

$$
P_{i j} \leq P_{i j, \max }
$$

\subsection{Uncertainties of EV Behaviors}

At a certain market scale, the factors affecting the electrical power demand of EVs can be summarized as the battery capacity, charging facilities, and user behavior. The battery capacity determines the user's charging frequency. A larger battery capacity will require a lower charging frequency. The charging power is also related to the battery capacity. A battery with a larger capacity will have a greater charging power. The charging power is also limited by the power level of the charging facilities. At the same time, the proportion of charging facilities will also affect the time distribution of the charging demand. For example, if the charging stations are set up both at home and at the workplace, drivers who need to drive EVs to work will form high-demand charging periods in the morning and at night. Compared with the objective factors above, user behavior is the key factor that affects the power demand of EVs, and it is random [37]. The user behavior that affects the charging demand of EVs mainly includes two factors: the beginning time of charging and the daily driving 
distance. The power grid needs to provide more charging power to EVs when the charging time is more concentrated. The daily driving distance reflects the power consumption of the users in a day. Therefore, the distribution of the charging power is decided by the charging power, beginning time of charging, and daily driving distance. This paper will build a mathematic model, which is based on the probability distribution of the three factors, to solve the uncertainty problem of user behavior.

Generally, vehicles can be divided into two categories: commercial vehicles and private vehicles. Commercial vehicles usually have a fixed driving route and parking place. The power demand of commercial vehicles can be expected to constitute a fixed mode. However, private vehicles are more flexible and random in terms of charging behavior and daily driving distance. Therefore, this paper focuses on private vehicles and their driving characteristics.

According to the analysis above, there are many aspects that can affect the charging demand. The following assumptions are made in this paper:

1) All EVs begin charging after their last trip.

2) All EVs are charged with a $0.1 \mathrm{C}$ rated current.

3) All EVs terminate their charge until full power.

4) The charging power, beginning time of charging, and daily driving distance are independent of each other.

A survey in 2001, from the national household travel survey (NHTS), showed that $14 \%$ of household vehicles were unused, $43.5 \%$ travelled for $20 \mathrm{~m}$ a day (about $32 \mathrm{~km}$ ), and $83.7 \%$ travelled for $60 \mathrm{~m}$ a day (about $97 \mathrm{~km}$ ) [38]. Maximum likelihood estimation is an application of the probability theory in statistics. It is one of the methods to estimate parameters. When a given random sample satisfies a certain probability distribution, with unclear specific parameters, maximum likelihood estimation can approximate the values of the parameters by observing the results of several tests. By observing two groups of data, the ending time of the last trip is found to satisfy a normal distribution, and the daily driving distance is found to satisfy a logarithmic normal distribution [39]. The probability density function of the ending time of the last trip and driving distance is shown in Figures 2 and 3. The final fitting result is shown as follows:

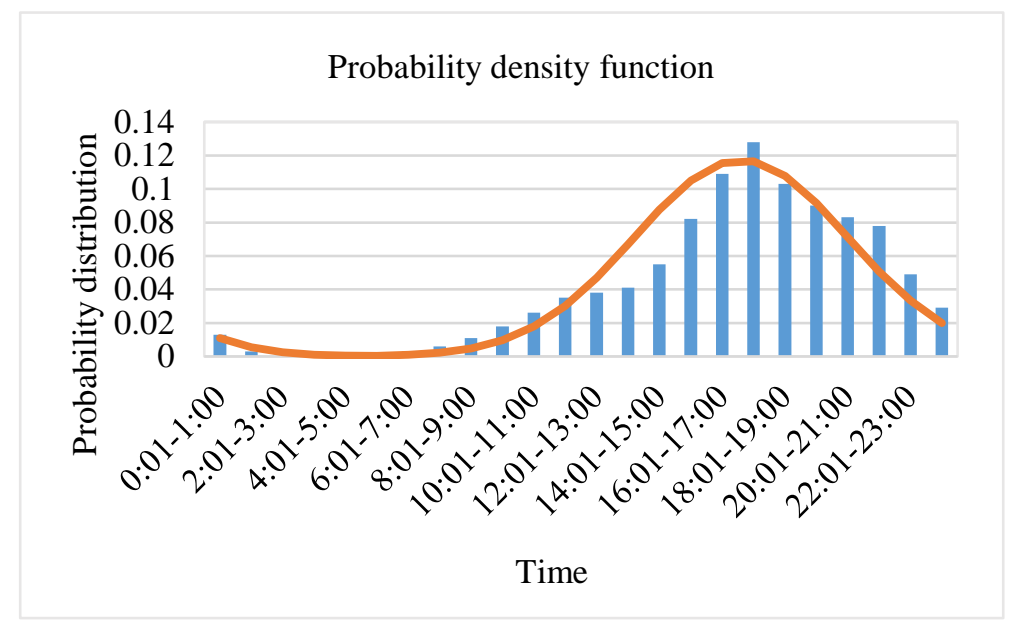

Figure 2. Probability density function of the ending time of the last trip. 


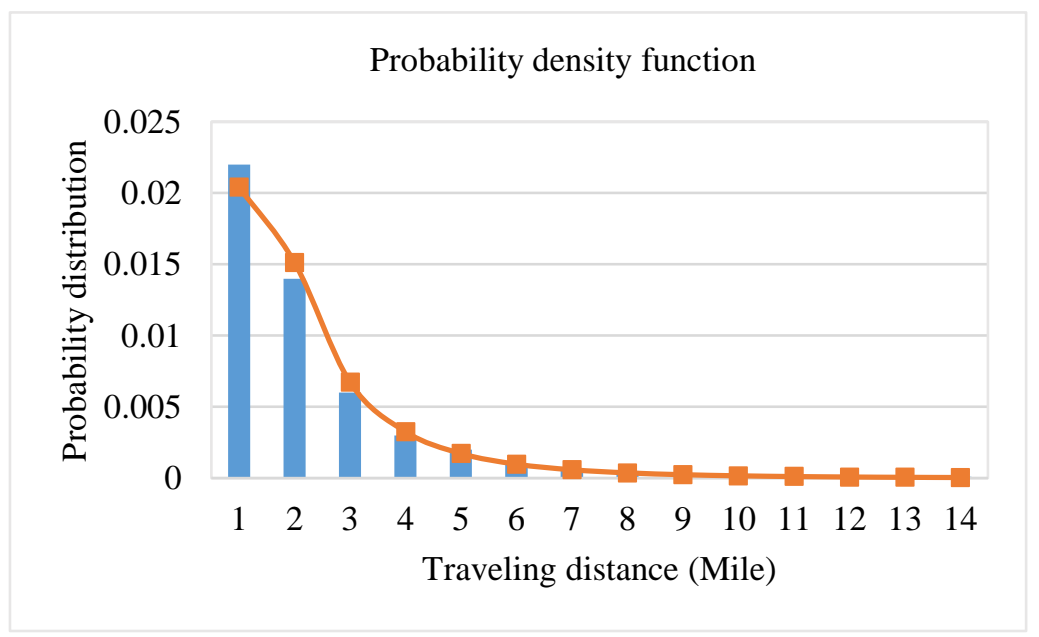

Figure 3. Probability density function of the driving distance.

Ending time of the last trip:

$$
f_{E}(x)=\left\{\begin{array}{cl}
\frac{1}{\sigma_{E} \sqrt{2 \pi}} \exp \left(-\frac{\left(x-\mu_{E}\right)^{2}}{2 \sigma_{E}^{2}}\right), & \left(\mu_{E}-12\right)<x \leq 24 \\
\frac{1}{\sigma_{E} \sqrt{2 \pi}} \exp \left(-\frac{\left(x+24-\mu_{E}\right)^{2}}{2 \sigma_{E}^{2}}\right), & 0<x \leq\left(\mu_{E}-12\right)
\end{array},\right.
$$

where $f_{E}$ is the probability distribution function of the ending time of the last trip: $\mu_{E}=17.6$ and $\sigma_{E}=3.4$.

Driving distance for one day:

$$
f_{D}(x)=\frac{1}{x \sigma_{D} \sqrt{2 \pi}} \exp \left(-\frac{\left(\ln x-\mu_{D}\right)^{2}}{2 \sigma_{D}^{2}}\right)
$$

where $f_{D}$ is the probability distribution function of the driving distance for one day: $\mu_{D}=3.20$ and $\sigma_{D}=0.88$.

At a certain charging current rate, the charging power of EVs is related to the battery capacity. Similar to the displacement difference of fuel vehicles, the battery capacity of domestic EVs is taken into consideration. In this paper, the battery capacity is assumed to be distributed in the range of 20-30 kWh. Currently, the power battery is mainly based on the constant current constant voltage charging mode [40]. In general, the charging characteristics of lead-acid and lithium-ion batteries are similar. The charging processes can be found in the literature [41], and we show the charging processes in Figure 4 . The actual charging process is close to the simplified charging process. The start and end stages of the charging process are much shorter than the whole charging process. Therefore, conventional slow charging can ignore these two stages in the charging process. During the constant current charging process, the charging power will change in accordance with the constant voltage at battery terminals. Considering that the simplified charging process is more conducive to mathematical simulation modeling, we assume that the charging process is a constant power characteristic in the simulation. 


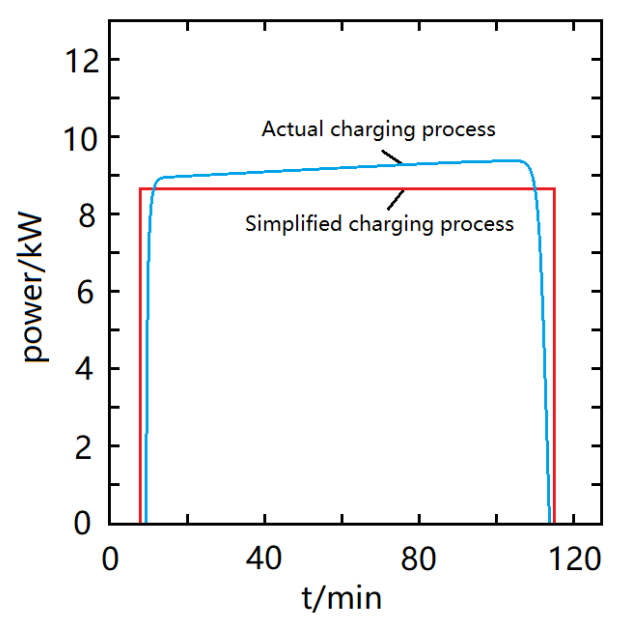

Figure 4. The simplified charging process.

Under the assumption of a $0.1 C$ charging rate current, the charging power $P_{C}$ of each EV satisfies a uniform distribution in the range of $2-3 \mathrm{~kW}$, which is the same as the distribution of the battery capacity, as shown in Figure 4.

$$
f_{P_{C}}(x)= \begin{cases}1, & x \in[2,3] \\ 0, & \text { otherwise }\end{cases}
$$

The charging time can be estimated by the following:

$$
T_{C}=\frac{S W_{100}}{100 P_{C}}
$$

According to the assumption, the daily driving distance of an EV is independent of its charging power. Therefore, the probability density function of the charging time can be obtained:

$$
f_{T_{C}}\left(T_{C}\right)=\int_{2}^{3} \frac{1}{T_{C} \sigma_{D} \sqrt{2 \pi}} \exp \left(-\frac{\left(\ln T_{C}+\ln P_{C}+\ln 1.61-\ln 0.15-\mu_{D}\right)^{2}}{2 \sigma_{D}^{2}}\right) \mathrm{d} P_{C}, T_{C}>0 .
$$

In order to obtain the charging state of an EV at a specific time $t_{0}$ in a day, parameter $\gamma$ must be created: $\gamma=1$ when the EV is charging, and $\gamma=0$ when the EV is not in the charging state.

$$
\begin{gathered}
P(\gamma=1)=1-F_{E T_{C}}\left(t>t_{0}, t+T_{C} \leq t_{0}+24\right)-F_{E T_{C}}\left(t+T_{C} \leq t_{0}\right) \\
P(\gamma=0)=F_{E T_{C}}\left(t>t_{0}, t+T_{C} \leq t_{0}+24\right)+F_{E T_{C}}\left(t+T_{C} \leq t_{0}\right) \\
F_{E T_{C}}=F_{E} F_{T_{C}}
\end{gathered}
$$

The charging start time is independent of the EV charging time. According to Equations (28)-(31), the number of charging EVs per minute can be estimated.

\subsection{Fuzzy Multi-Objective Model}

The EV charging model proposed in this paper is a typical multi-objective problem. We hope that in the distribution network, the captured traffic will be maximized, and the power loss will be minimized.

$$
\left\{\begin{aligned}
\max F_{t f} & =\sum_{p \in P} f_{p} y_{p} \\
\min F_{p l} & =\sum_{i=1}^{n} P_{\text {loss }}\left(\delta_{i} P_{i, k}, \delta_{i} Q_{i, k}\right)
\end{aligned}\right.
$$


The two objectives cannot reach the optimal solution at the same time. Therefore, functions $\lambda\left(F_{t f}\right)$ and $\lambda\left(F_{p l}\right)$ are employed to transfer both sub-objectives into two piecewise functions, whose values vary from 0 to 1 .

$$
\begin{gathered}
\lambda\left(F_{t f}\right)= \begin{cases}0 & , F_{t f} \leq F_{1}-\eta_{1} \\
\frac{F_{t f}-F_{1}+\eta_{1}}{\eta_{1}} & , F_{1}-\eta_{1}<F_{t f} \leq F_{1} \\
1 & , F_{t f}>F_{1}\end{cases} \\
\lambda\left(F_{p l}\right)= \begin{cases}\frac{1}{F_{2}-F_{p l}+\eta_{2}} & , F_{p l} \leq F_{2} \\
\eta_{2} & , F_{2}<F_{p l} \leq F_{2}+\eta_{2}\end{cases}
\end{gathered}
$$

As shown in Figure 5, the membership function is used to fuzz two sub-objectives into one objective, and $\lambda$ is employed here to represent this membership function.

$$
\lambda=\min \left[\lambda\left(F_{t f}\right), \lambda\left(F_{p l}\right)\right]
$$

Objective:

$$
\max \lambda
$$

Limitation:

$$
\begin{gathered}
-F_{t f}+\eta_{1} \lambda \leq-F_{1}+\eta_{1}, \\
F_{p l}+\eta_{2} \lambda \leq F_{2}+\eta_{2}, \\
0 \leq \lambda \leq 1 .
\end{gathered}
$$

Function (37) is employed to ensure that $F_{t f}$ is larger than $F_{1}-\eta_{1}$, and Function (38) is employed to ensure that $F_{p l}$ is lower than $F_{2}+\eta_{2}$. The parameters in the functions above can be calculated by Functions (33)-(36):

$$
\left\{\begin{array}{l}
F_{1}=F_{t f, 1} \\
F_{2}=F_{p l, 2} \\
\eta_{1}=F_{t f, 1}-F_{t f, 2} \\
\eta_{2}=F_{p l, 1}-F_{p l, 2}
\end{array} .\right.
$$

where $F_{t f, 1}$ is the theoretical maximum captured traffic flow, and $F_{p l, 1}$ is the corresponding total power loss in this condition; $F_{p l, 2}$ is the theoretical minimum total power loss, and $F_{t f, 2}$ is the corresponding captured traffic flow; and $\eta_{1}$ and $\eta_{2}$ are the difference between the two captured traffic flow values and the two total power loss values, respectively.
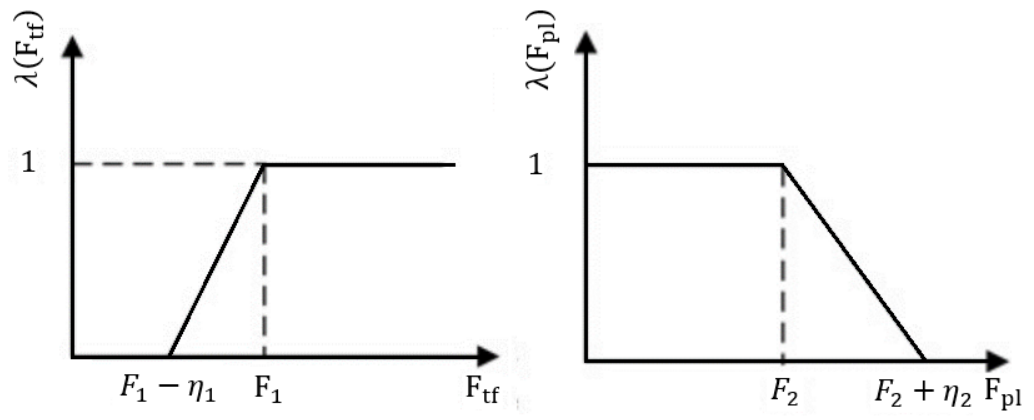

Figure 5. Membership function. 


\section{Case Studies}

\subsection{Setup}

The EV selected for the case study is the Toyota RAV4 [42]. The characteristics of the Toyota RAV4 are shown in Table 1. Considering Table 1, the driving distance $L$ of the EV, with a full charged battery, is assumed to be $150 \mathrm{~km}$. According to a survey in 2001, from the national household travel survey (NHTS), $14 \%$ of household vehicles were unused [43]. Therefore, the usage rate $\zeta$ is assumed to be $14 \%$. The setting of some crucial parameters is shown in Table 2 [39], and we have changed some of the values. As we know, the maximum charging load of the EV is closely related to the number of EVs, charging power, battery capacity, and users' habits. There are currently no reliable statistical data reflecting users' habits, because EVs have not been widely used. Therefore, the relevant data concerning fuel vehicles are used to replace EVs in the case study analysis in this paper.

Table 1. The data for Toyota RAV4.

\begin{tabular}{ccc}
\hline Symbol & Description & Value \\
\hline Bcap & Battery Capacity & $27 \mathrm{kWh}$ \\
Bweigh & Battery Weight & $551 \mathrm{~kg}$ \\
& Number of Battery Modules & 24 \\
& Weight of Battery Module & $21 \mathrm{~kg}$ \\
& Nominal Module Voltage & $12 \mathrm{~V}$ \\
& Nominal System Voltage & $288 \mathrm{~V}$ \\
$L_{\max }$ & Maximal Range & $190 \mathrm{~km}$ \\
$L_{\min }$ & Minimal Range & $130 \mathrm{~km}$ \\
$L$ & Average Range & $150 \mathrm{~km}$ \\
\hline
\end{tabular}

Table 2. Setting of some crucial parameters.

\begin{tabular}{cccc}
\hline Parameters & Value & Parameters & Value \\
\hline$L$ & $150 \mathrm{~km}$ & $N$ & 5000 \\
$\tau$ & 5 & $W_{100}$ & $15 \mathrm{kWh}$ \\
$P_{C p}$ & $3 \mathrm{~kW}$ & $M_{i}$ & 100 \\
$P_{F C S}$ & $35 \mathrm{~kW}$ & $W^{\text {allowed }}$ & $5 \mathrm{~min}$ \\
$\zeta$ & $14 \%$ & $S_{\min }$ & 5 \\
$\xi$ & $80 \%$ & $S_{\max }$ & 10 \\
$\omega$ & 3 & & \\
\hline
\end{tabular}

The power time series used for this paper is drawn from the literature [44]. According to the analysis of the daily driving distance and average charging time of EVs in the uncertainty part, the charging number of EVs per minute in a day is obtained. We plot the curves for the charging number of EVs per minute in Figure 6. On the basis of the assumption above, the time when over $80 \%$ of EVs use the charging service is the peak charging period, which is from $998 \mathrm{~min}$ to $1303 \mathrm{~min}$ in this simulation. Therefore, the FCSs only operate at 17:00, 18:00, 19:00, 20:00, and 21:00. 


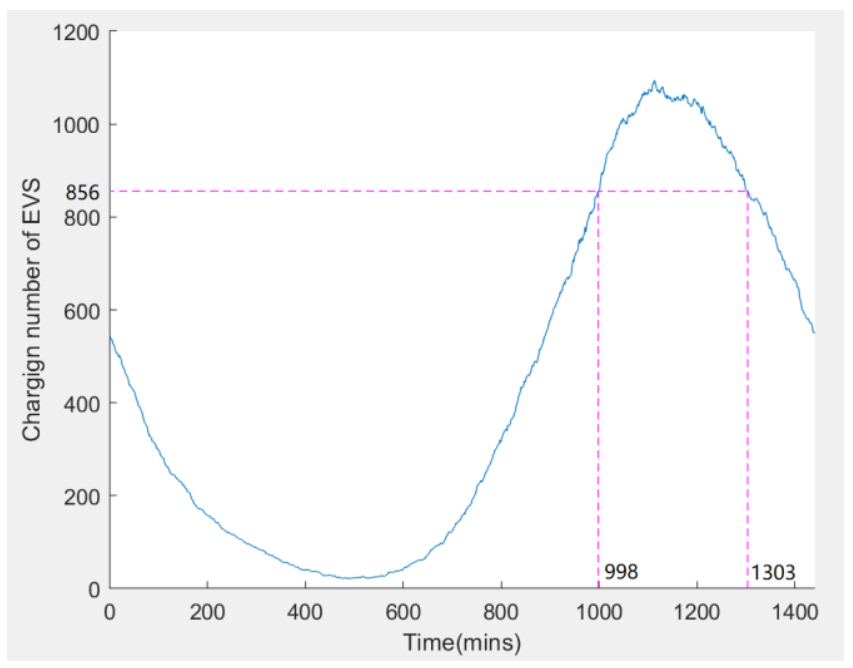

Figure 6. The mean number of charging electric vehicles (EVs).

According to a survey from New York's dynamic power grid [45], the data are collected by the U.S. electrical system. The seasonal hourly electricity demand patterns for 2017 in New York are shown in Figure 7, and the analysis in this paper will be based on the electricity demand in summer. The feasibility and effectiveness of the proposed model are illustrated by the IEEE 33-node distribution network and the 25-node traffic network. The distribution network data are from the work of [41], and we consider the system and load parameters in this paper. The traffic network data are from the work of [46], but are adjusted to accommodate the distribution network. The following assumptions are adopted: the traffic network nodes 1,2,, 25 coincide with the distribution network nodes 1, 2, $\ldots, 25$. The actual connectivity traffic network and distribution network are shown in Figures 8 and 9 , respectively. The number of charging stations required is four. The maximum driving distance of an EV is set to $L$. The node weight is set according to the degree of demand at each traffic node, as shown in Table 3.

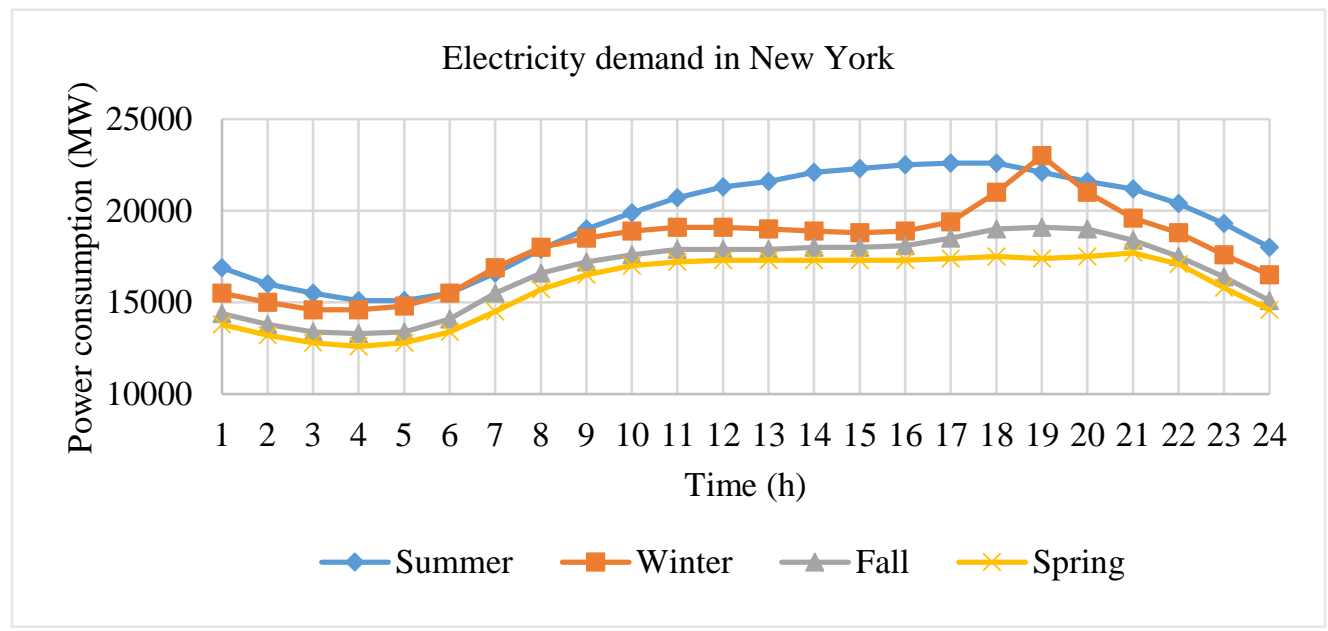

Figure 7. Electrical consumption in New York. 


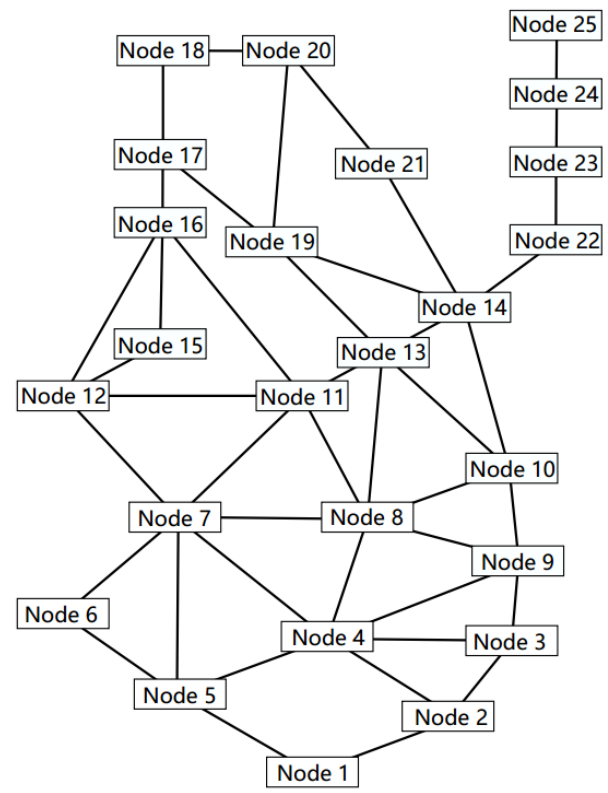

Figure 8. The 25-node traffic network.

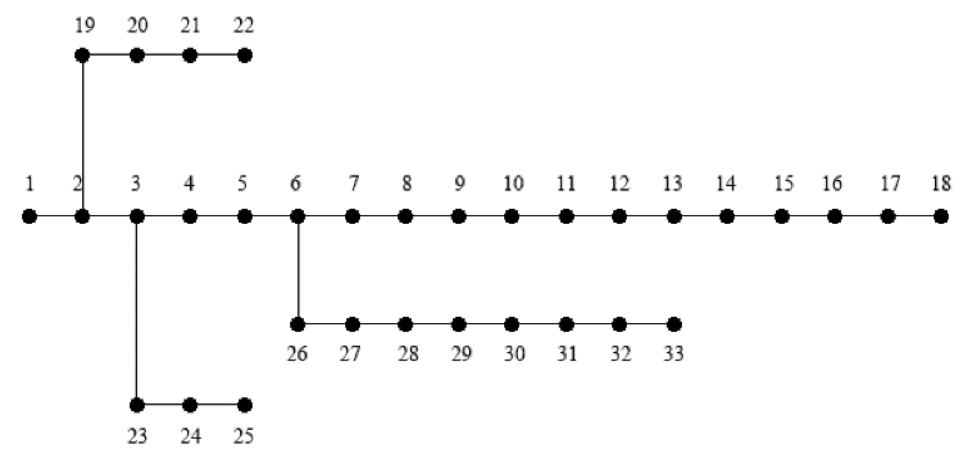

Figure 9. The 33-node distribution network.

Table 3. Weight of various traffic nodes.

\begin{tabular}{cccccc}
\hline Node & $\begin{array}{c}\text { Weight } \\
\text { Coefficient }\end{array}$ & Node & $\begin{array}{c}\text { Weight } \\
\text { Coefficient }\end{array}$ & Node & $\begin{array}{c}\text { Weight } \\
\text { Coefficient }\end{array}$ \\
\hline 1 & 0.54 & 10 & 0.54 & 19 & 0.80 \\
2 & 0.80 & 11 & 0.05 & 20 & 0.27 \\
3 & 0.27 & 12 & 0.54 & 21 & 0.27 \\
4 & 0.27 & 13 & 0.05 & 22 & 0.54 \\
5 & 0.27 & 14 & 0.54 & 23 & 0.05 \\
6 & 0.07 & 15 & 0.27 & 24 & 1.34 \\
7 & 0.05 & 16 & 0.27 & 25 & 0.05 \\
8 & 0.54 & 17 & 0.27 & & \\
\hline
\end{tabular}

According to the captured traffic flow model, the two FCSs are located at nodes 14 and 10, which have the highest and the second highest traffic flow in this traffic network, respectively. In the case of optimizing each objective function separately, the obtained minimum value of the network loss is $166.0392 \mathrm{~kW}$, and the maximum value of the captured traffic flow is $0.3674(60.12 \%$ of the total traffic flow), as shown in Table 4. 
Table 4. Result of the sub-objectives.

\begin{tabular}{ccc}
\hline $\begin{array}{c}\text { Location of Charging } \\
\text { Stations }\end{array}$ & $\begin{array}{c}\text { Maximum Captured Traffic Flow } \\
\mathbf{0 . 3 6 7 4} \mathbf{( 6 0 . 1 2} \% \text { of Total Traffic Flow) }\end{array}$ & $\begin{array}{c}\text { Minimum Power Loss } \\
\mathbf{1 6 6 . 0 3 9 2 ~} \mathbf{~ W W}\end{array}$ \\
\hline Station 1 & 2 & 1 \\
Station 2 & 8 & 2 \\
Station 3 & 14 & 19 \\
Station 4 & 17 & 25 \\
\hline
\end{tabular}

In order to fuzz the two objectives together, the parameters of the normalization method above can be calculated:

$$
\begin{gathered}
F_{t f, 1}=0.3674, \\
F_{p l, 2}=166.0392 .
\end{gathered}
$$

The responding traffic flow and power loss, when the power loss is at its minimum and the traffic flow is at its maximum, respectively, are

$$
\begin{gathered}
F_{t f, 2}=0.1370, \\
F_{p l, 1}=493.4421 .
\end{gathered}
$$

There, the parameters of the fuzzy function are

$$
\begin{gathered}
F_{1}=F_{t f, 1}=0.3674, \\
F_{2}=F_{p l, 2}=166.0392, \\
\eta_{1}=F_{t f, 1}-F_{t f, 2}=0.2304, \\
\eta_{2}=F_{p l, 1}-F_{p l, 2}=327.4029 .
\end{gathered}
$$

The ultimate genetic algorithm is used to find the optimal solution. According to the selected number of nodes, the length of the GA chromosome is set at 14, the size of the initial population size is 50 , the maximum evolutionary algebra is set to 120 , the crossover probability is 0.5 , and the mutation probability is 0.2 .

\subsection{Results and Discussion}

Figure 10 illustrates the planning results of the proposed multi-objective model. The multi-objective model is built with objectives maximizing the captured traffic flow and minimizing power loss in the distribution networks. As shown in the plots, the abscissa and ordinate values are the captured traffic flow and the power loss, respectively. In general, the two objectives cannot be directly used for multi-objective optimization. It is necessary to transform the maximum traffic flow into an appropriate objective. Therefore, we have converted the maximized captured traffic $\max F_{t f}$ (Equation (1)) and $\min F_{p l}$ (Equation (4)) into one objective $\min \lambda$ (Equation (35)) using the membership functions (see Figure 5). As we know, GA is an effective method for solving multi-objective optimization problems.

Moreover, the non-dominated solutions and the Pareto frontier, obtained from the distributed coupled system (a 33-node distribution system and a 25-node traffic network), are shown in Figure 10. In Figure 10, the captured traffic flow ranges from 0.1307 to 0.3674 , and the power loss ranges from 166.0392 to 493.4421 . Given this Pareto frontier, the investor could easily make a proper trade-off between these two conflicting objectives. A fuzzy satisfaction decision-making approach in the literature [47] was used to select the appropriate solution (selected solution) in this paper. One non-dominated solution, as pointed out in Figure 10, is selected as the final result. Furthermore, the selected final planning result is described in Table 5. 


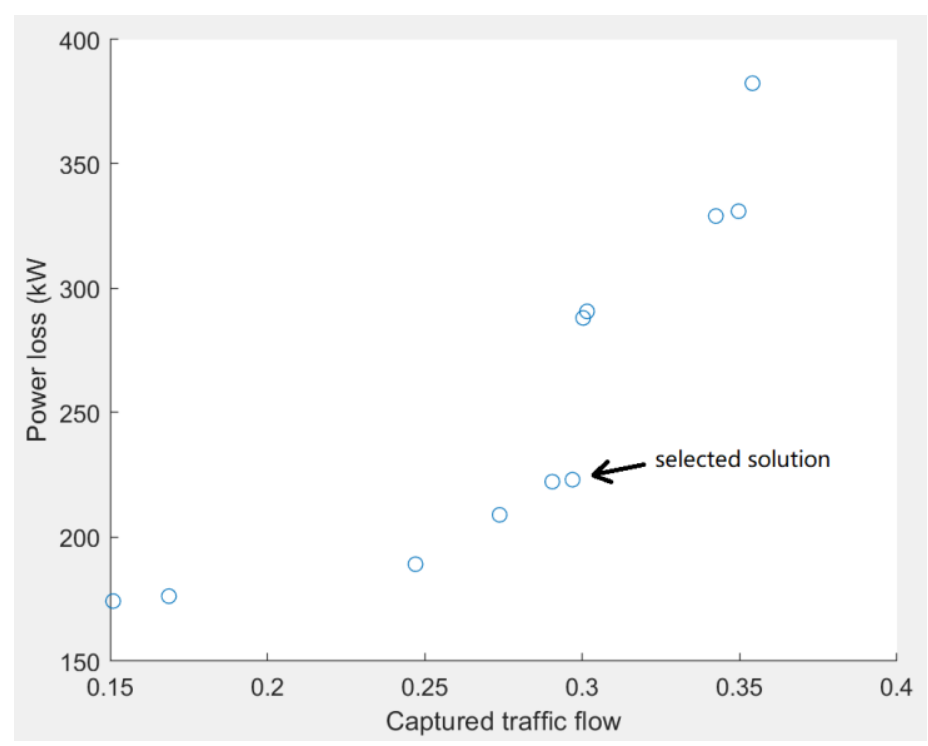

Figure 10. Pareto frontier, obtained by the proposed model.

Table 5. Result of the selected solution.

\begin{tabular}{ccc}
\hline $\begin{array}{c}\text { Location of Normal } \\
\text { Charging Stations }\end{array}$ & Capacity of Normal Charging Stations & $\begin{array}{c}\text { Location and Size of } \\
\text { FCSs }\end{array}$ \\
\hline Station 1: 3 & Station 1: 0.3 MW & Location of Station 1: 14 \\
Station 2: 8 & Station 2: 0.6 MW & Location of Station 2: 10 \\
Station 3: 19 & Station 3: $0.7 \mathrm{MW}$ & Size of Station 1: 5 \\
Station 4: 22 & Station 4: 0.7 MW & $0.2901(47.47 \%$ of total traffic flow $)$ \\
\hline $\begin{array}{c}\text { Captured traffic flow } \\
\text { Power loss }\end{array}$ & $222.9647 \mathrm{~kW}$ \\
\hline
\end{tabular}

The corresponding graphical topology of the selected final planning scheme of the coupled 25-node traffic network and 33-node distribution network is displayed in Figure 11. We can see that four normal charging stations and two FCSs are plotted with squares and triangles, respectively. For the final planning, it can be found that four normal charging stations are located at nodes $3,8,9$, and 12, and two FCSs are located at nodes 10 and 14. The final result shows a captured traffic flow of 0.2091 ( $47.47 \%$ of total traffic flow) and a power loss of $222.9647 \mathrm{~kW}$ (more information is provided in Table 5). Compared with the optimal result of the sub-objectives (the captured traffic flow or power loss only), the captured traffic flow decreases from 0.3674 (60.12\% of the total traffic flow) to 0.2901 (47.47\% of the total traffic flow), and the power loss increases from $166.0392 \mathrm{~kW}$ to $222.9647 \mathrm{~kW}$. From the result of the sub-objective, in order to maximize the captured traffic flow, the charging stations are mainly constructed in transport hubs, which have a higher node weight. With a higher traffic flow through the node, the planned charging station can provide a charging service for more EVs, while in order to minimize the power loss of the distribution network, the charging stations with a high capacity are mainly constructed on the front end of a system feeder. 


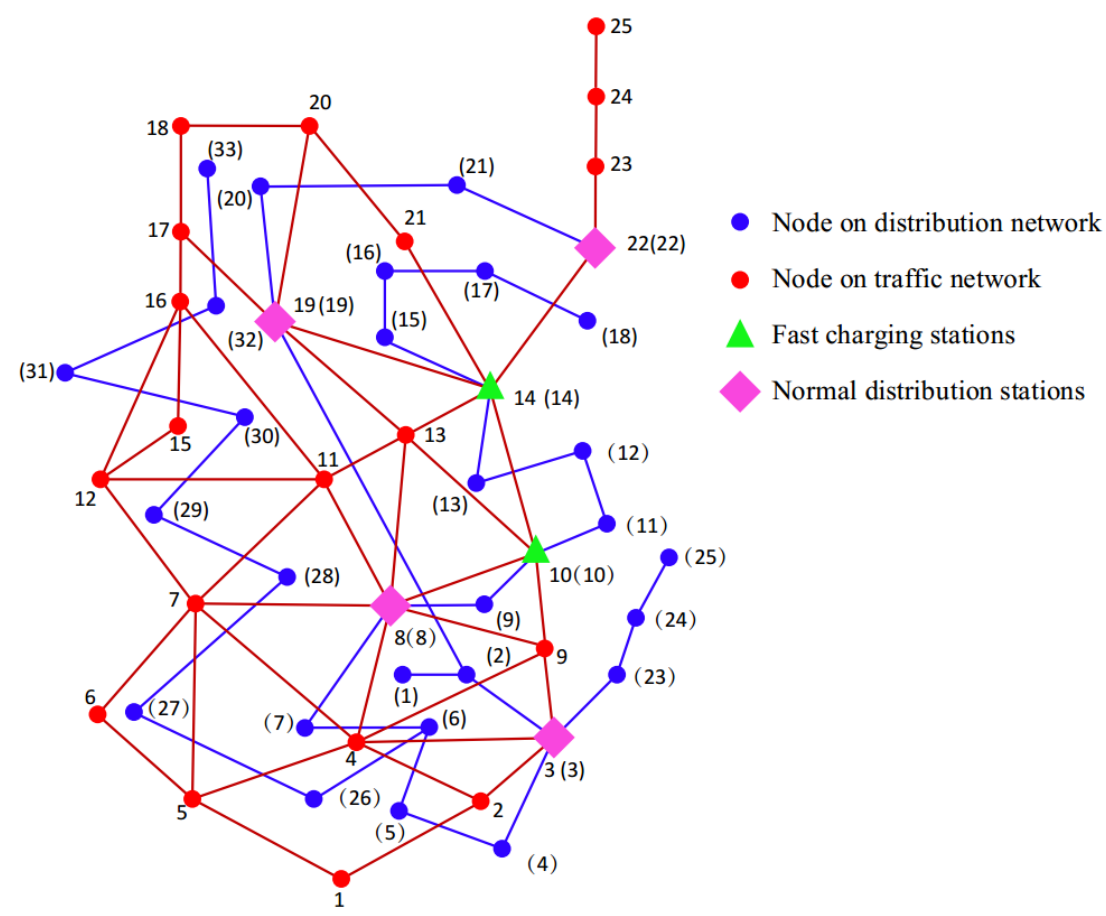

Figure 11. Graphical topology of the selected final planning scheme of the coupled 25-node traffic network and 33-node distribution network.

After the location and capacity of the charging stations have been determined, the impact of the maximum traveling distance on the captured traffic flow is further analyzed. Figure 12 shows a study of the traffic flows, captured in relation to the different maximum traveling distances. It can be seen, from Figure 12, the longer the maximum travel distance of EVs, the more EVs can be serviced by charging stations, when the charging station location has been determined. When $L$ is larger than $421 \mathrm{~km}$, it will no longer have an impact on the captured traffic flow, and the maximum captured traffic flow is $62.87 \%$. This makes sense, because the larger battery capacity will allow the electric car drivers to enjoy longer driving distances, without having to frequently stop at a charging station. With the presently imperfect charging stations, a limited number of charging stations can service more EVs by increasing the capacity of the traveling distance, which is very important for the development of EVs.

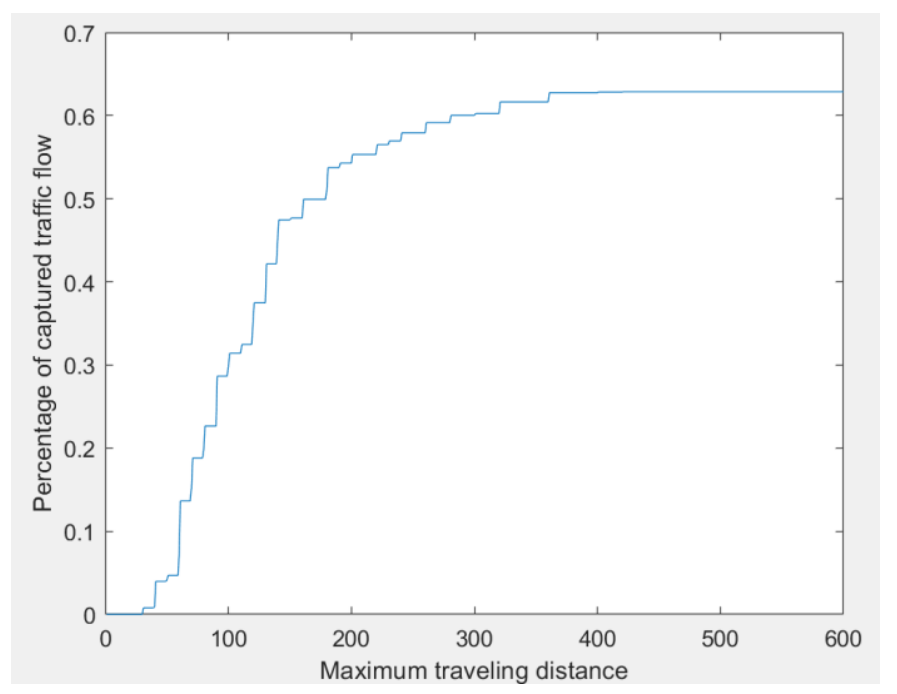

Figure 12. Percentage of the captured traffic flow for different maximum traveling distances. 


\section{Conclusions and Future Research Challenge}

This paper presents a multi-objective model, which is built with the objective of maximizing the captured traffic flow in traffic networks and minimizing the power loss in distribution networks. There are two kinds of charging stations that are considered in this paper, and the planning of EV charging stations and distribution networks are jointly modelled. Unlike previous research, this paper simultaneously considers both the distribution network and traffic network in one system using the fuzzy multi-objective model. Second, the charging model, considered during different time periods, can better simulate the charging behavior of EVs. The model proposed in this paper can balance the two conflicting objectives and find an optimal solution. According to the case study results, in order to maximize the captured traffic flow, the charging stations are mainly constructed at transport hubs, which have a higher node weight. With a higher traffic flow through the node, the planned charging station can provide a charging service for more EVs. However, in order to minimize the power loss of the distribution networks, the charging stations with a high capacity are mainly constructed on the front end of a system feeder. Moreover, the longer the maximum traveling distance of EVs, the more EVs can be serviced by charging stations, when the charging station location has been determined.

The model proposed in this paper is based on an assumption that all EVs travel along the shortest path to their destination. In practice, the driving path can be influenced by traffic jams and driver negligence. How to solve this uncertainty problem more accurately is a further research objective. In addition, V2G constitutes a major development tendency of EVs, as it not only shares the pressure of the power grid, but also reduces the cost for consumers. Thus, V2G is an important part that can be added into this model in future work.

Author Contributions: G.L. proposed the methodological framework and mathematical model and drafted the manuscript; Z.L. performed the simulations, J.Q. reviewed and improved the methodological framework and implementation algorithm; and F.Z. and L.K. reviewed the manuscript and provided suggestions.

Funding: This work was supported by The National Key Research and Development Program of China (2017YFB0,903,205) and Research start-up funds of DGUT (GC300502-10).

Conflicts of Interest: The authors declare no conflict of interest.

\section{Nomenclatures}

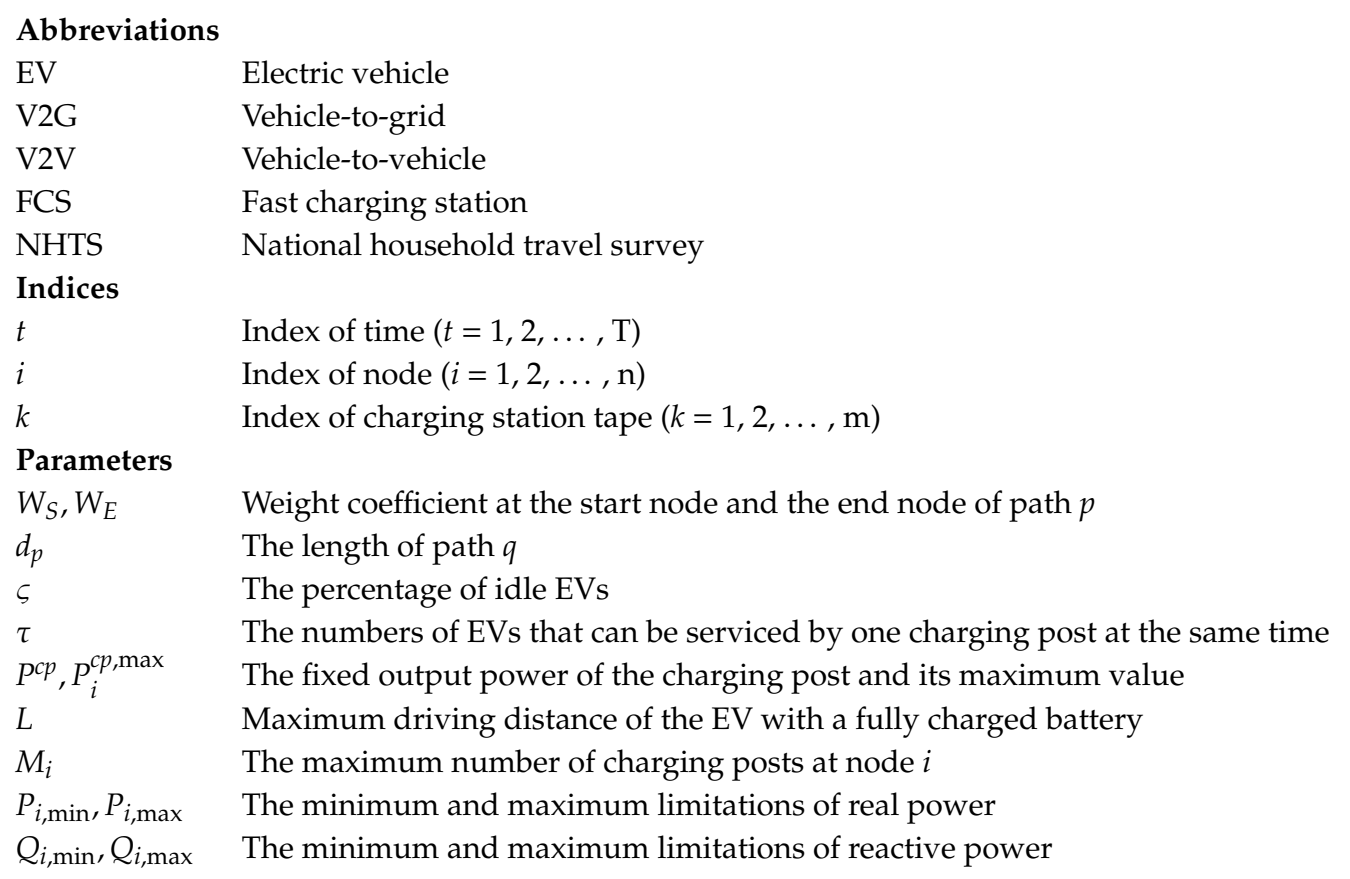


$P_{i j}, P_{i j, \max } \quad$ The actual power flow between nodes $i$ and $j$ and its maximum value

$T_{C} \quad$ Charging time of EVs

$S \quad$ Daily driving distance of EVs

$W_{100} \quad$ Electricity consumption per $100 \mathrm{~km}$ of EVs

$P_{C} \quad$ Charging power of EVs

$F_{t f, 1}, F_{p l, 1} \quad$ The theoretical maximum captured traffic flow and the corresponding total power loss

$F_{t f, 2}, F_{p l, 2} \quad$ The theoretical minimum total power loss and the corresponding captured traffic flow

$\mu_{E}, \mu_{D} \quad$ Distribution expectation of the ending time of the last trip and the driving distance

$\sigma_{E}, \sigma_{D} \quad$ Standard deviation of the ending time of the last trip and the driving distance

$N \quad$ Total number of EVs

$\xi \quad$ The percentage of EVs that choose a normal charging station

$s_{\min }, s_{\max } \quad$ Minimum size and maximum size of FCSs

$\omega \quad$ Mean service rate of FCSs

$\lambda_{k}^{P K} \quad$ Mean arrival rate of EVs in the kth FCS during the peak charging time period

$W_{k}^{P K}, W^{\text {allowed }} \quad$ Waiting time in the kth FCS during the peak time period and its maximum value

$\rho_{k}^{P K} \quad$ Occupied rate of the kth FCS

Variables

$F_{t f}$

The total captured traffic flow of the traffic network

$f_{p} \quad$ Traffic flow on path $\mathrm{p}$

$f_{k} \quad$ Captured traffic flow by the $k$ th fast charging station

$y_{p} \quad y_{p}=1$ if path $q$ is refuellable; 0 , if not

$v_{i, t} \quad$ The numbers of EVs that charge at node $i$ at time $t$

$a_{p, g} \quad$ A binary variable that characterizes whether or not the node combination $h$ is effective; 1 is effective, 0 is not

$v_{g} \quad$ A binary variable that characterizes whether or not all the nodes in the node combination are set up at the charging station; 1 is yes, and 0 is no

$\varphi_{i, k} \quad$ A binary variable that characterizes whether or not the type $k$ station is set up at node $i ; 1$ is yes, and 0 is no

$P_{i, k} \quad$ Charging power of the type $k$ charging station at node $i$

$\gamma \quad$ A binary variable that characterizes whether or not the electrical vehicle is charging; 1 is yes, and 0 is no

\section{Functions}

$F_{E T_{C}}$

$F_{E}$

The joint probability distribution function of the charging start time and charging time

Probability distribution function of the ending time of the last trip

Probability distribution function of the driving distance for one day

$F_{T_{C}} \quad$ Probability density function of the charging time

\section{References}

1. Kikusato, H.; Mori, K.; Yoshizawa, S.; Fujimoto, Y.; Asano, H.; Hayashi, Y.; Kawashima, A.; Inagaki, S.; Suzuki, T. Electric vehicle charge-discharge management for utilization of photovoltaic by coordination between home and grid energy management systems. IEEE Trans. Smart Grid 2018, 10, 3186-3197. [CrossRef]

2. Yong, W.; Yang, G.; Ying, D.; Yu, C.; Shang, P. The scale, structure and influencing factors of total carbon emissions from households in 30 provinces of china-Based on the extended stirpat model. Energies 2018, 11, 1125.

3. Abul'Wafa, A.R.; Mohamed, W.A.F. Impacts of Uncoordinated and Coordinated Integration of Electric Vehicles on Distribution Systems Performance. In Proceedings of the 2017 Nineteenth International Middle East Power Systems Conference (MEPCON), Cairo, Egypt, 19-21 December 2017; IEEE: Piscataway, NJ, USA, 2017; pp. 337-364.

4. Wang, Z.; Tang, Y.; Xiao, C.; Men, X.; Cao, J.; Wang, H. Optimized daily dispatching strategy of building-integrated energy systems considering vehicle to grid technology and room temperature control. Energies 2018, 11, 1287. [CrossRef]

5. Kempton, W.; Tomić, J. Vehicle-to-grid power implementation: From stabilizing the grid to supporting large-scale renewable energy. J. Power Sources 2005, 144, 280-294. [CrossRef] 
6. Kempton, W.; Letendre, S.E. Electric vehicles as a new power source for electric utilities. Transp. Res. Part D Transp. Environ. 1997, 2, 157-175. [CrossRef]

7. Brooks, A.N. Vehicle-To-Grid Demonstration Project: Grid Regulation Ancillary Service with a Battery Electric Vehicle; California Environmental Protection Agency, Air Resources Board, Research: Sacramento, CA, USA, 2002.

8. Han, S.; Han, S.; Sezaki, K. Economic Assessment on v2g Frequency Regulation Regarding the Battery Degradation. In Proceedings of the 2012 IEEE PES Innovative Smart Grid Technologies (ISGT), Washington, DC, USA, 16-18 January 2012; IEEE: Piscataway, NJ, USA, 2012; pp. 1-6.

9. Tomić, J.; Kempton, W. Using fleets of electric-drive vehicles for grid support. J. Power Sources 2007, 168, 459-468. [CrossRef]

10. Han, S.; Han, S.; Sezaki, K. Development of an optimal vehicle-to-grid aggregator for frequency regulation. IEEE Trans. Smart Grid 2010, 1, 65-72.

11. Xi, X.; Sioshansi, R.; Marano, V. Simulation-optimization model for location of a public electric vehicle charging infrastructure. Transp. Res. Part D Transp. Environ. 2013, 22, 60-69. [CrossRef]

12. Sadeghi-Barzani, P.; Rajabi-Ghahnavieh, A.; Kazemi-Karegar, H. Optimal fast charging station placing and sizing. Appl. Energy 2014, 125, 289-299. [CrossRef]

13. Escudero-Garzás, J.J.; García-Armada, A.; Seco-Granados, G. Fair design of plug-in electric vehicles aggregator for v2g regulation. IEEE Trans. Veh. Technol. 2012, 61, 3406-3419. [CrossRef]

14. Galus, M.D.; Koch, S.; Andersson, G. Provision of load frequency control by phevs, controllable loads, and a cogeneration unit. IEEE Trans. Ind. Electron. 2011, 58, 4568-4582. [CrossRef]

15. Ota, Y.; Taniguchi, H.; Nakajima, T.; Liyanage, K.M.; Baba, J.; Yokoyama, A. Autonomous distributed v2g (vehicle-to-grid) satisfying scheduled charging. IEEE Trans. Smart Grid 2011, 3, 559-564. [CrossRef]

16. Liu, H.; Hu, Z.; Song, Y.; Lin, J. Decentralized vehicle-to-grid control for primary frequency regulation considering charging demands. IEEE Trans. Power Syst. 2013, 28, 3480-3489. [CrossRef]

17. Deng, B.; Wang, Z. Research on electric-vehicle charging station technologies based on smart grid. In Proceedings of the 2011 Asia-Pacific Power and Energy Engineering Conference, Wuhan, China, 25-28 March 2011; IEEE: Piscataway, NJ, USA, 2011; pp. 1-4.

18. Tulpule, P.; Marano, V.; Yurkovich, S.; Rizzoni, G. Energy economic analysis of pv based charging station at workplace parking garage. In Proceedings of the IEEE 2011 EnergyTech, Cleveland, OH, USA, 25-26 May 2011; IEEE: Piscataway, NJ, USA, 2011; pp. 1-6.

19. Clement-Nyns, K.; Haesen, E.; Driesen, J. The impact of charging plug-in hybrid electric vehicles on a residential distribution grid. IEEE Trans. Power Syst. 2009, 25, 371-380. [CrossRef]

20. Leou, R.-C.; Su, C.-L.; Lu, C.-N. Stochastic analyses of electric vehicle charging impacts on distribution network. IEEE Trans. Power Syst. 2013, 29, 1055-1063. [CrossRef]

21. Taylor, J.M.A.; Alexander, M.; Brooks, D.; Duvall, M. Evaluation of the impact of plug-in electric. In IEEE PES General Meeting; IEEE: Piscataway, NJ, USA, 2009.

22. Chen, Q.; Liu, N.; Wang, C.; Zhang, J. Optimal power utilizing strategy for pv-based ev charging stations considering real-time price. In Proceedings of the 2014 IEEE Conference and Expo Transportation Electrification Asia-Pacific (ITEC Asia-Pacific), Beijing, China, 31 August-3 September 2014; IEEE: Piscataway, NJ, USA, 2014; pp. 1-6.

23. Sundstrom, O.; Binding, C. Flexible charging optimization for electric vehicles considering distribution grid constraints. IEEE Trans. Smart Grid 2011, 3, 26-37. [CrossRef]

24. Yang, J.; Yang, Z. Optimal scheduling of electric vehicle using dual decomposition. In Proceedings of the The 26th Chinese Control and Decision Conference (2014 CCDC), Changsha, China, 31 May-2 June 2014; IEEE: Piscataway, NJ, USA, 2014; pp. 2144-2149.

25. You, P.; Yang, Z.; Chow, M.-Y.; Sun, Y. Optimal cooperative charging strategy for a smart charging station of electric vehicles. IEEE Trans. Power Syst. 2015, 31, 2946-2956. [CrossRef]

26. You, P.; Yang, Z. Efficient optimal scheduling of charging station with multiple electric vehicles via v2v. In Proceedings of the 2014 IEEE International Conference on Smart Grid Communications (SmartGridComm), Venice, Italy, 3-6 November 2014; IEEE: Piscataway, NJ, USA, 2014; pp. 716-721.

27. Bashash, S.; Moura, S.J.; Forman, J.C.; Fathy, H.K. Plug-in hybrid electric vehicle charge pattern optimization for energy cost and battery longevity. J. Power Sources 2011, 196, 541-549. [CrossRef] 
28. Sojoudi, S.; Low, S.H. Optimal charging of plug-in hybrid electric vehicles in smart grids. In Proceedings of the 2011 IEEE power and energy society general meeting, Detroit, MI, USA, 24-29 July 2011; IEEE: Piscataway, NJ, USA, 2011; pp. 1-6.

29. Deilami, S.; Masoum, A.S.; Moses, P.S.; Masoum, M.A. Real-time coordination of plug-in electric vehicle charging in smart grids to minimize power losses and improve voltage profile. IEEE Trans. Smart Grid 2011, 2, 456-467. [CrossRef]

30. Wu, C.; Mohsenian-Rad, H.; Huang, J. Vehicle-to-aggregator interaction game. IEEE Trans. Smart Grid 2011, 3, 434-442. [CrossRef]

31. Caramanis, M.; Foster, J.M. Management of electric vehicle charging to mitigate renewable generation intermittency and distribution network congestion. In Proceedings of the $48 \mathrm{~h}$ IEEE Conference on Decision and Control (CDC) held jointly with 2009 28th Chinese Control Conference, Shanghai, China, 15-18 December 2009; IEEE: Piscataway, NJ, USA, 2009; pp. 4717-4722.

32. Wang, G.; Zhang, X.; Wang, H.; Peng, J.C.; Liu, W. Robust planning of electric vehicle charging facilities with advanced evaluation method. IEEE Trans. Ind. Inform. 2017, 14, 866-876. [CrossRef]

33. Fang, H.; Di, W.; Yin, Y.; Guan, Y. Optimal deployment of public charging stations for plug-in hybrid electric vehicles. Transp. Res. Part B Methodol. 2013, 47, 87-101.

34. Fotheringham. Spatial Interaction Models:Formulations and Applications; Kluwer Academic Publishers: Dordrecht, The Netherlands, 1989.

35. Ogden, K.W. The distribution of truck trips and commodity flow in urban areas: A gravity model analysis. Transp. Res. 1978, 12, 131-137. [CrossRef]

36. Kontou, E.; Liu, C.; Xie, F.; Wu, X.; Lin, Z. Understanding the linkage between electric vehicle charging network coverage and charging opportunity using gps travel data. Transp. Res. Part C Emerg. Technol. 2019, 98, 1-13. [CrossRef]

37. Bradley, T.H.; Quinn, C.W. Analysis of plug-in hybrid electric vehicle utility factors. J. Power Sources 2010, 195, 5399-5408. [CrossRef]

38. Tayloe, J.; Maitra, A.; Alexander, M.; Brooks, D.; Duvall, M. Evaluation of the impact of plug-in electric vehicle loading on distribution system operations. In Proceedings of the General Meeting 2009 IEEE Power Engineering Society, Calgary, AL, Canada, 26-30 July 2009; pp. 1-6.

39. Yao, W.; Zhao, J.; Wen, F.; Xue, Y.; Ledwich, G. A hierarchical decomposition approach for coordinated dispatch of plug-in electric vehicles. IEEE Trans. Power Syst. 2013, 28, 2768-2778. [CrossRef]

40. Vu, V.-B.; Tran, D.-H.; Choi, W. Implementation of the constant current and constant voltage charge of inductive power transfer systems with the double-sided lcc compensation topology for electric vehicle battery charge applications. IEEE Trans. Power Electron. 2018, 33, 7398-7410. [CrossRef]

41. Qian, K.; Zhou, C.; Allan, M.; Yue, Y. Modeling of load demand due to ev battery charging in distribution systems. IEEE Trans. Power Syst. 2011, 26, 802-810. [CrossRef]

42. Kadurek, P.; Ioakimidis, C.; Ferrao, P. Electric vehicles and their impact to the electric grid in isolated systems. In Proceedings of the 2009 International Conference on Power Engineering, Energy and Electrical Drives, Lisbon, Portugal, 18-20 March 2009; IEEE: Piscataway, NJ, USA, 2009; pp. 49-54.

43. Collia, D.V.; Joy, S.; Lee, G. The 2001 national household travel survey: A look into the travel patterns of older americans. J. Saf. Res. 2003, 34, 461-470. [CrossRef]

44. Bessa, R.J.; Matos, M.A.; Soares, F.J.; Lopes, J.A.P. Optimized bidding of a ev aggregation agent in the electricity market. IEEE Trans. Smart Grid 2011, 3, 443-452. [CrossRef]

45. Balancing Authority Electricity Demand. Available online: https://www.eia.gov/realtime_grid/\#/data/graphs? end $=20170907$ T00\&start $=20170831$ T00\&bas $=000 \mathrm{~g} \&$ regions $=0$ (accessed on 10 October 2017).

46. Simchilevi, D.; Berman, O. A heuristic algorithm for the traveling salesman location problem on networks. Oper. Res. 1988, 36, 478-484. [CrossRef]

47. Yao, W.; Zhao, J.; Wen, F.; Dong, Z.; Xue, Y.; Xu, Y.; Meng, K. A multi-objective collaborative planning strategy for integrated power distribution and electric vehicle charging systems. IEEE Trans. Power Syst. 2014, 29, 1811-1821. [CrossRef]

(C) 2019 by the authors. Licensee MDPI, Basel, Switzerland. This article is an open access article distributed under the terms and conditions of the Creative Commons Attribution (CC BY) license (http://creativecommons.org/licenses/by/4.0/). 